\title{
Creation of a NFC Reading System for University Attendance Monitoring with Accessibility Considerations for Powered Wheelchair Users.
}

\author{
Giles Tewkesbury, David Sanders, Malik Haddad, Peter Omoarebun, Alexander Gegov and Simon Chester \\ Faculty of Technology, University of Portsmouth \\ Portsmouth, UK \\ giles.tewkesbury@port.ac.uk
}

\begin{abstract}
This paper considers the hardware and software implementation of a Near-Field Communication (NFC) reading system which was used to collect student attendance information in a two-year study with University Engineering students. Learning analytics has become popular with an increase in attendance monitoring activity across the higher education sector. This paper presents a bespoke in-house attendance monitoring system and has been created in the School of Engineering to conduct research to consider the benefits of such a system for staff and students. The paper highlights some of the technical decisions and challenges faced during the implementation of the trial system and considers the accessibility of the system for powered wheelchair users. Electronic card reader hardware was purchased and installed in selected rooms in the University as part of a faculty of technology learning and teaching grant looking at Attendance monitoring. The study has concluded that the introduction of an electronic card reader system at the University of Portsmouth would not cause unacceptable delays for students entering classrooms and would contribute positively to student experience, however accessibility measures would need to be put in place to enable powered wheelchair users to engage with the system at all locations across the University premises.
\end{abstract}

Keywords- NFC; RFID; attendance; monitoring; wheelchair; accesability

\section{INTRODUCTION}

The School of Engineering at the University of Portsmouth collected student attendance information by either passing around a sign-in sheet or a roll call during lectures. Historically there was a reluctance to pursue formalised attendance monitoring due to differing views on perceived benefits [1 - 4]. With the introduction of the UK border agency Tier 4 Sponsor licenses and the associated monitoring requirements, there was a fresh drive to formalised attendance monitoring. Manual, paper-based attendance monitoring processes were considered time consuming and tedious for both students and staff. The accuracy of some paper registers was questionable where students were only required to tick against their name.

Review studies have investigated a link between attendance and student performance and achievement across different subject domains [4-6]. Studies often have struggled to isolate attendance from the effect of other variables, such as motivation, past performance and preparation on attendance and student performance [6]. However, many studies present a correlation between student attendance and performance [7-11]. More specifically in engineering subjects, a number of studies show a strong correlation between attendance and performance [12-17].

The trial system presented in this paper was used to investigate the use of NFC readers to establish if such a system could automate the process of taking attendance registers whilst improving the accuracy of information collected and providing positive staff and student experience.

This paper explains the hardware / firmware development and the NFC technologies employed in the research for both static and mobile NFC readers. The selection of location and height of readers was considered with consideration of accessibility for users of powered electric wheelchairs.

The software architecture for the trial system is presented along with the visual feedback protocol for student registrations.

A trial group of academic staff were selected to use the electronic card readers to assist with taking the class register. Students were asked, by academic staff, to present their cards to the electronic reader on entry to the classroom. At the end of the study staff and students were presented with a questionnaire to ascertain their perception of the system.

The accuracy of the register data collected was investigated and both staff and students were aware that some students were abusing the system by giving their cards to other students to register, when they were not present. Student and staff experience questions indicated that over $95 \%$ of staff and $80 \%$ of students preferred using the electronic card reading system compared to other conventional means for taking registers.

Results from the trial are discussed and conclusions and recommendations made for hardware, placement of readers and accessibility. The software architecture is reviewed in light of the trial results and an improved system configuration is presented. 


\section{HARDWARE AND FIRMWARE DEVELOPMENT}

Students enrolled at the University were supplied with an identification card that had an NFC MIFARE IC which stores the student ID number in an encrypted form. Since all students were required to carry the cards whilst on campus, the use of NFC technology in the attendance monitoring system was considered optimal.

\section{A. NFC Technology}

Near Field Communication (NFC) is a short-range form of RFID (Radio-Frequency Identification) which was originally based on the ISO 14443 standard for transactions. This standard limited the range to typically 0 - 20 centimetres [19]. However, NFC has now incorporated the ISO 15693 standard, which offered a maximum read range of about 1 meter. NFC can work with both active and passive devices.

Active devices such as mobile phones, have an integral power supply which can enable longer range communication. Passive devices are powered through energy transferred from the $\mathrm{RF}$ field of the reader and therefore require a very high signal strength from the reader to the tag, restricting the reading range for these devices.

\section{B. Static Readers}

The static readers used in the project were 'Orbit IP' card readers manufactured by Gemini 2000 Ltd. These devices were TCP/IP, Ethernet-based RFID terminals for contactless smart cards. They use Power-over-Ethernet, so a separate, external power supply was not required.

The Orbit IP devices operated as standalone HTTP web clients. When a contactless card was detected by a reader, it sent a HTTP GET request to the web server. The server responded with standard HTTP reply to the reader. The content of the response controlled the sounding of a beeper and illumination of LED indicators on the device.

The reader's firmware was customised to extract and decrypt student ID data before sending it on to the ingestion server. The centre LED's that was used to indicate that the device was active was changed from amber to blue.
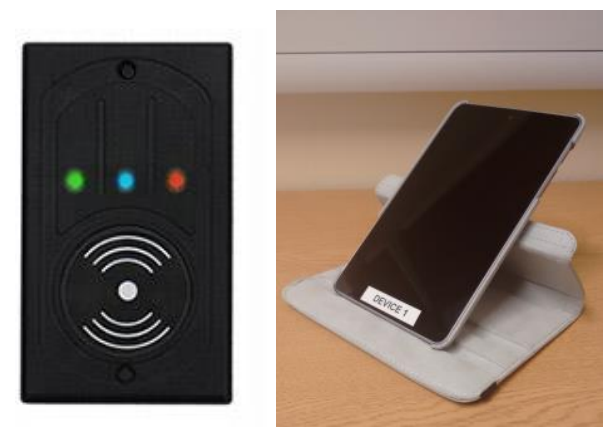

Figure 1. Orbit IP card reader (left) and a portable reader (Right)

\section{Portable Readers}

The trial system incorporated the use of mobile readers able to be booked for a location, and used to register students attendance at that location. Some mobile phones and tablet devices are equipped with appropriate NFC readers, for example Nokia models 5140i (see Fig 1) and 6131. Such devices are small in size, have a long battery life, can connect to the internet and can be used as ordinary mobile phones.

An Android app was created that used the tablet's NFC device to read campus cards and send that data to the ingestion server (over Wi-Fi).

The app allowed students to register manually and without using their campus card, by typing-in their student ID number using an on-screen keyboard. The app also worked on mobile phones that had NFC capabilities.

Use of these tablet devices was not constrained to specific rooms or members of staff. Therefore, before using a tablet device to register students at an event, it was necessary to associate that device with the class to be registered. This was done by requiring lecturers to swipe their staff card at the beginning (or just before) an event, so that students could subsequently be registered.

After each registration attempt, a message briefly appeared on screen to indicate whether or not registration had been successful. An audible sound was used to indicate that a campus card had been read successfully.

\section{Selection of Card Reader Locations}

The University had a total of around 400 teaching rooms. About $10 \%$ of these would be classed as large space (for 60-200 students), with only two rooms over the size of 200 .

The selection of rooms for use in the trial system encompassed different styles of lecture theatre with differing access arrangements and a classroom. Table I shows the selected rooms and location of the static card readers.

TABLE I. LOCATIONS OF SATAIC CARD READERS

\begin{tabular}{|c|c|c|c|c|}
\hline Room & Size & Type & Readers & Location \\
\hline 1 & 131 & $\begin{array}{l}\text { Lecture } \\
\text { Theatre }\end{array}$ & 1 & Right hand side outside of door \\
\hline 2 & 128 & $\begin{array}{l}\text { Lecture } \\
\text { Theatre }\end{array}$ & 2 & $\begin{array}{l}\text { Right hand side outside of door } \\
\text { Left hand side outside of door }\end{array}$ \\
\hline 3 & 200 & $\begin{array}{l}\text { Lecture } \\
\text { Theatre }\end{array}$ & 2 & $\begin{array}{l}\text { Inside; Right hand side of wall } \\
\text { Inside; left hand side of wall }\end{array}$ \\
\hline 4 & 121 & $\begin{array}{l}\text { Lecture } \\
\text { Theatre }\end{array}$ & 1 & Inside; Left hand side. \\
\hline 5 & 146 & $\begin{array}{l}\text { Class- } \\
\text { room }\end{array}$ & 1 & Right hand side outside of door \\
\hline 6 & 123 & $\begin{array}{l}\text { Lecture } \\
\text { Theater }\end{array}$ & 2 & $\begin{array}{l}\text { Inside; on column at top of stairs } \\
\text { Inside; Column near lectern }\end{array}$ \\
\hline
\end{tabular}

Part $\mathrm{M}$ of the UK building regulations [18] advises that switches and sockets servicing habitable rooms should have their centre line between $4521200 \mathrm{~mm}$ above floor level, to assist people who have reduced reach. For the card reader system to be accessible to students operating powered wheelchairs, it was decided to adopt the policy of installing readers at a height of $1200 \mathrm{~mm}$ above floor level. 


\section{SOFTWARE ARCHITECTURE}

Fig 2 shows the software for the card reading system. The system was designed using a task oriented approach [18]. Students registered at events by scanning their cards on card readers. Those registrations were sent to an ingestion server. The purpose of the ingestion server was to receive and capture registration information from card readers and ensure a timely response to card readers. The ingestion server would respond to the card readers to indicate if the card had been read successfully and if the student was on the attendance list for that class. The Ingestion server responses controlled which lights to illuminate and whether or not to emit a sound.

Initially, the following response scheme was used:

- When a student successfully registered, a green light was illuminated for half a second and a short beep emitted from the card reader.

- When a student registration failed, a red light was illuminated for a second and a longer beep was emitted.

- When a student attempted to register at an event but didn't appear on the class list (i.e. they weren't expected to attend that event) then both the red and green lights were illuminated simultaneously and a beep was emitted.

Since there was a series of communications that had to take place before the card read was visually acknowledged, the response time for the server was a design concern and so a diagnostic logging server was created to monitor the system.

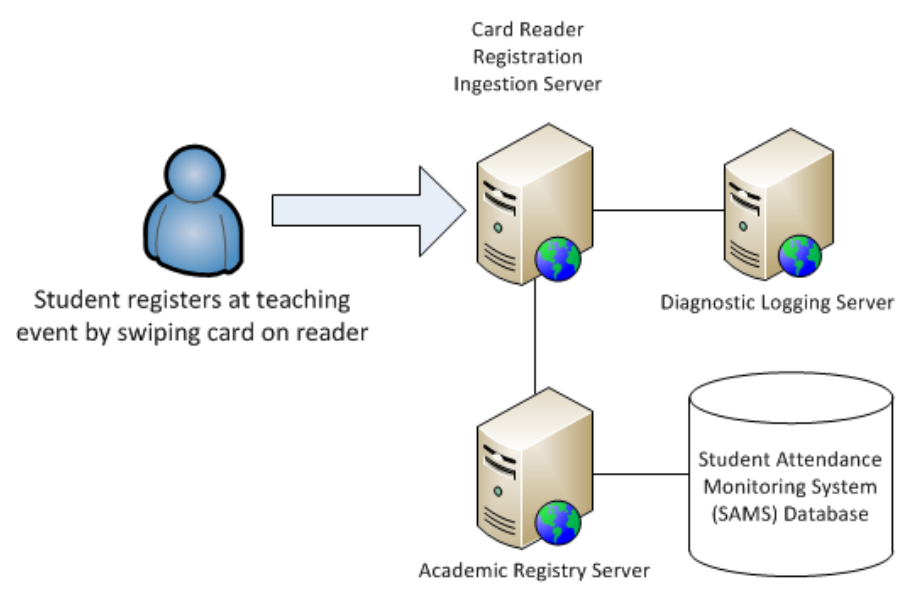

Figure 2. NFC reader system architecture

The diagnostic logging server receive data from the ingestion server and captured usage data that could be analysed for assessing the performance of the card reading system and identifying / diagnosing problems. Some specific uses of this diagnostic logging system were:

- Monitoring the availability of card readers (to identify card reader devices that may have faults or not functioning).
- Identifying and monitoring the number of successful registrations by device and room.

- Monitoring the speed of registrations (i.e. the time between scanning a card and receiving an acknowledgment that registration had or hadn't occurred).

- Monitoring the number of failed registrations (i.e. cases where students swiped a card but the card reader couldn't read the student's number from the card).

The ingestion server interfaced to existing university corporate systems, which provided timetabling information and populated student attendance records. These systems were supported by the academic Registry Systems Development \& Support team (RSDS). The interface used to the corporate systems was via a proprietary Application programming interface (API) that allowed the card reader system to communicate with the Student Attendance Monitoring System (SAMS) and the CMIS timetabling system. The specific tasks performed using these API's were:

- Get Events For Room Location: Used to discover what event is currently occurring (or about to start) in a given room.

- $\quad$ Register Student: Instructs the SAMS to record a student as attending a specific event. Responses from this API confirmed whether or not the student was expected to attend the event (i.e. if they were on the class list).

\section{STAFF AND STUDENT PARTICIPATION}

Academic staff who were timetabled to teach in rooms with the card readers were identified and those with a reasonable number of events were invited to participate in the study. From the 156 members of staff approached, 61 agreed to participate in the trial by using the electronic card readers to assist with taking class registers at compulsory events. Students were asked to present their cards to the electronic card reader on entry to a room. At the end of the study staff and students were asked to complete a questionnaire about their experiences. A participant information sheet was provided to staff and made available to students participating in the study. Taking part in the study was voluntary. Students however were required to participate in the university's student attendance monitoring, and although participation in the electronic card reader registration was optional, there were alternative means for students to register their attendance at the selected sessions. Students were able to opt-out by simply not presenting their card to the electronic reader. Participation in feedback was also optional and anonymous.

At teaching events, participating staff provided a paper signin sheet so that students without cards could register their attendance. Staff were asked to return the paper sign in sheet to indicate that the session was part of the trial. Table II details the number of forms that were returned and processed. 
Students were able to participate by presenting their cards at the card reader and 4992 unique students did this. Students who had used their cards to register for six or more events were selected to participate in the student feedback questionnaire (3367 students) and of these 532 students completed the questionnaire.

TABLE II. SIGN IN FORMS PROCESSED

\begin{tabular}{|l|l|}
\hline Total sheets returned & 403 \\
\hline Sheets ignored in weeks $1 \& 2$ & 43 \\
\hline Incorrectly filled in & 19 \\
\hline Not processed (Late returns) & 82 \\
\hline Not processed (Excess Names on List) & 24 \\
\hline
\end{tabular}

A Google form survey was used to obtain feedback from staff and students involved in the trial. 60 members of academic staff who had indicated that they were willing to be a part of the trial were emailed the staff feedback questionnaire and $42 \%$ (25) responded. Students who had used their cards to register for six or more events were selected to participate in the student feedback questionnaire, and these 3367 students were emailed the survey, of which, 16\% (532) responded.

\section{RESULTS}

The electronic card reading system was extensively used both for events within the trial and other events by staff not involved in the trial. Table III shows the extent to which the system was used: processed.

\section{TABLE III. SYSTEM USAGE DURING TRIAL}

\begin{tabular}{|c|c|}
\hline $\begin{array}{c}\text { Number of student cards scanned at } \\
\text { timetabled events }\end{array}$ & 113,753 \\
\hline $\begin{array}{c}\text { Number of unique students who scanned } \\
\text { their cards one or more times. }\end{array}$ & 4,922 \\
\hline $\begin{array}{c}\text { Number of Timetabled events where one } \\
\text { or more students scanned their cards }\end{array}$ & 2,570 \\
\hline $\begin{array}{c}\text { Number of courses that registered students } \\
\text { were enrolled on: }\end{array}$ & 150 \\
\hline
\end{tabular}

Fig 3 shows the distribution of the number of students who were at the trial events. It can be seen that a majority of the events had between 50 and 75 students present.

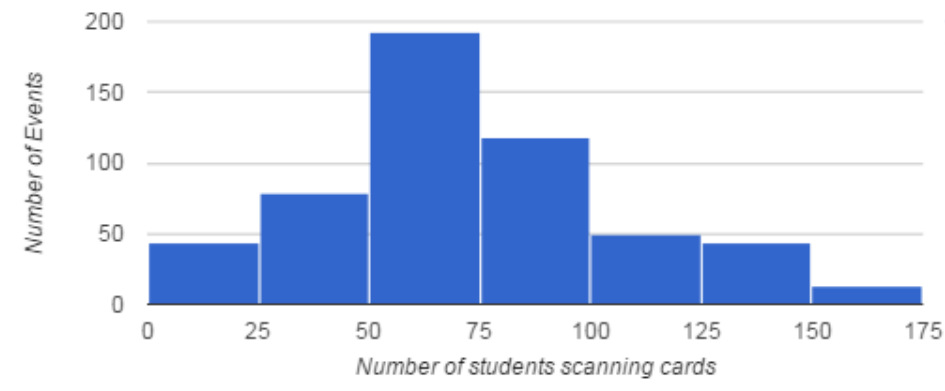

Figure 3. Distribution of number of students at trial events

\section{A. Feedback from Staff and Students}

Over $95 \%$ of staff and $80 \%$ of students preferred using the electronic card reading system compared to other conventional means (e.g. paper registers or roll calls). However, it was noted (by $72 \%$ of students) that sometimes the card readers did not read a cards on the first attempt.

$38 \%$ of students and $25 \%$ of staff were aware of misuse of the system by students scanning their cards then leaving without attending the session. A more serious misuse of the system was also identified where students would give their cards to others to scan with $28 \%$ of staff and $22 \%$ of students were aware of this practice. This behaviour may have been accentuated by the fact that the data from the trial was fed into the SAMS attendance monitoring system, and therefore student non-attendance would lead to consequences.

When asked about the location of card readers, $60 \%$ staff said they preferred card readers to be located inside the room.

\section{B. Card Reading Responses}

Early feedback from participants suggested that students weren't looking at the indicator lights and were relying on listening for a beep to determine whether or not they'd successfully registered. During the trial the responses were changed so that a beep was only emitted when registration was successful. This removed any possibility that the duration of a beep could be misinterpreted.

\section{Ingestion System Errors}

Some of the problems that were encountered by the ingestion system were:

- Card Reading Errors: The card readers sometimes failed to read the student number from student cards when they were presented to the card readers. Metrics collected from the diagnostic logs indicate that about $9 \%$ all registration attempts from static card readers failed.

- Academic Registry API Errors: Registrations weren't deemed to have been successful until the Academic Registry server confirmed that they had been stored in the SAMS database. A number of problems sometimes occurred during that process:

- $\quad$ Excessive response times: On occasions the Registry API took a long time to reply to registration requests. Delays 
exceeding 580ms were deemed to be excessive. During the trial, the ingestion system was improved by introducing a 'Presumptive OK' system.

- 'Double-tapping' faults: Early in the system's life, problems arose because the static card readers attempted to read cards again, immediately after successfully reading them. A filtering process was introduced so that 'doubletaps' were effectively ignored.

- No or invalid response: On some occasions the Registry API server was unavailable or gave an invalid response. In these cases, errors were logged and the ingestion system administrator was notified by email so that failed registrations could be manually recorded in SAMS later (when the registry API was available again or fixed).

- Arbitrary event selections: On some occasions, more than one event was timetabled in the same location simultaneously. In these cases the ingestion system arbitrarily selected an event and attempted to register students to that event.

\section{CONSIDERATIONS FOR POWERED WHEELCHAIR USERS}

This section discusses the problems of using the NFC reading system for powered wheelchair users. The placement of the card readers was carefully chosen so that students entering a room did not need to turn to present their card to the reader. The height of the reader was selected at $1.2 \mathrm{~m}$ so that powered wheelchair users could reach the reader. To scan the card, the wheelchair user would need to be able to reach up with either arm to present a card to the card reader. For wheelchair users who had the ability to move their arms however lacked the dexterity to hold a card, it was possible to source bracelets which contained the a Mifare NFC chip and the system was programmed to be able to recognise these in place of the official student cards. For students who did not have the ability to present a card to the card reader, it was not possible for them to scan a card since the card readers used during the project were only able to read cards in the range $0-5 \mathrm{~cm}$. NFC has however incorporated the ISO 15693 standard which extends the read range to about $1 \mathrm{~m}$. New devices built to the ISO 15693 standard might allow a powered wheelchair user to simply drive past the reader, which would register their attendance. This however was not available at the time of the project.

\section{CONCLUSIONS AND RECOMMENDATIONS}

The project has investigated the use of electronic card readers, identified ways in which they could interface with existing University systems and considered appropriate positions suitable for powered wheelchair users. Overall feedback from staff and students indicated a preference for the use of electronic card readers over traditional methods for collecting attendance. The results from this study have led to University of Portsmouth implementing a new electronic card reading system for attendance monitoring across all timetabled teaching space.

\section{A. Hardware}

The use of NFC technology in the attendance monitoring system was possible because all students were already required to carry University ID cards containing an NFC MIFARE IC which stored the student's ID number in an encrypted form. The study identified that students and staff were aware of students misusing the system for example, by either scanning their cards and leaving or passing cards onto other students to scan in their place. Additionally, during the study, students who had forgotten their cards were allowed to register in the paper system, however in a fully automated system these students would not be registered when they were present. In a system that uses NFC technology, these two issues would need to be considered to maintain the integrity of data.

The cost and complexity of systems associated with the portable readers was high, and the administration involved in controlling and maintaining these devices was not trivial. The study concluded that a more comprehensive approach would be to ensure that every timetabled space had a static reader installed, which would eliminate the need for portable readers, and the associated systems.

Placement of readers and accessibility considerations for Powered wheelchair users.

The placement of readers was reviewed following the trial, with the following recommendations:

- Height of NFC readers should be $1.2 \mathrm{~m}$ from the floor where possible to allow accessibility for wheelchair users.

- $\quad$ Students should be able to scan their cards without turning whilst entering the room. (NFC readers should be in line of sight whilst entering the room).

- Where possible the NFC readers should be placed inside the rooms. (but not in positions that required students to turn when entering the room).

- If NFC readers need to be outside the room then they should be placed close to the opening side of the door.

The trial concluded that these recommendations could not always be observed. For example, one of the University's buildings had ornate tiled walls up to a height of $1.5 \mathrm{~m}$ and positioning readers at this height would cause accessibility issues for powered wheelchair users. In these situations, active NFC devices could be used which require an external power supply. These devices could be fitted to powered wheelchairs and powered from the batteries that supply power to the motors and controller.

\section{B. Software Architecture}

The trial indicated that students did not understand or pay attention to the lights and mainly responded to the audio beeps to indicate a successful registration.

Successfully registrations were indicated with a green light and a short beep. However, when a student attempted to register at an event but didn't appear on the class list then a red light was illuminated and no sound was emitted. 
When a student registration failed i.e. the card was not recognised as a student card, then no response was given.

Analysis of data collected during the trial by the diagnostic logging server demonstrated that the Ingestion server was able to process the traffic associated at times of peak demand on the system, however the response from the academic registry server APIs was not consistent.

The APIs interfaced to existing university corporate systems provided timetabling information and populated student attendance records. The ingestor required a response from the corporate systems before it responded to the card reader to indicate the success of the student's registration. The response of the corporate systems depended on a number of external factors such as server loading. This led to a somewhat random response time which affected the users experience as indicated in the student feedback. To mitigate this a revised software architecture is recommended to allow a decoupling of the ingestors response from the process of registering a student in the corporate systems. This would require the caching of timetabled locations (rooms) and the students expected at those locations to enable the ingestor to respond with the correct information to students.

During this study there was no direct feedback to students about the attendance. A further recommendation would be that all attendance data collected about a student is made visible to the student to allow verification of the data collected.

\section{REFERENCES}

[1] J. Muir, "Student attendance: is it important, and what do students think?" CEBE Transactions, vol. 6, no. 2, ISSN: 1745-0322. 2009, pp. 50-69

[2] D. R. Marburger, "Does mandatory attendance improve student performance?" J. Econ. Educ., 37(2), 2006, pp. 148-155. doi: 10.3200/JECE.37.2.148-155.

[3] P. Massingham, and T. Herrington, "Does attendance matter? An examination of student attitudes, participation, performance and attendance," J. University Teaching \& Learning Practice, vol. 3, no. 2, ISBN 978-1-86137-668-8, 2006.

[4] G. Tewkesbury, S. Chester, D. Sanders, and M. Malik, "Monitoring attendance and its impact on engineering students," Realising Ambitions: Proceedings of the 6th Annual Symposium of the United Kingdom \& Ireland Engineering Education Research Network. Portsmouth, 20 April 2019, pp. 116-128.

[5] S.J. Dollinger, A. M. Matyja, and J. L. Huber, "Which factors best account for academic success: those which college students can control or those they cannot?" J. research in Personality, vol. 42 no. 4, 2008. pp.872-885.

[6] M. Schneider, and F. Preckel, "Variables associated with achievement in higher education: a systematic review of metaanalyses," Psychol Bull, vol. 143, no. 6, 2017, p. 565

[7] M. Credé, S. G. Roch, and U. M. Kieszczynka, "Class attendance in college: a meta-analytic review of the relationship of class attendance with grades and student characteristics," Rev Educ Res, vol. 80, no. 2, 2010, pp. 272-295.

[8] A. M. Anikeef, "The relationship between class absences and college grades," J. Educ Psychol, vol. 45, no. 4, 1954, p. 244.
[9] D. Gatherer, and F. C. Manning, "Correlation of examination performance with lecture attendance: a comparative study of firstyear biological sciences undergraduates," Biochem Educ, 26 (2), 1998, pp. 121-123.

[10] L. Newman-Ford, K. Fitzgibbon, S. Lloyd, and S. Thomas, "A large-scale investigation into the relationship between attendance and attainment: a study using an innovative, electronic attendance monitoring system," Stud High Educ, vol. 33, no. 6, 2008, pp. 699-717.

[11] P. Lockwood, C. Guppy and R. Smyth, "Should lectures be compulsory?" In Proceedings of the Australian Conference on Science and Mathematics Education (formerly UniServe Science Conference), October 2006.

[12] P. Purcell, September. "Engineering student attendance at lectures: effect on examination performance," In Int Conf on Engineering Education, Coimbra, Portugal. 2007.

[13] A. Nyamapfene, "Does class attendance still matter?" Eng Educ, vol. 5, no. 1,, 2010, pp. 64-74.

[14] S. Obeidat, A. Bashir, and W. A. Jadayil, "The importance of class attendance and cumulative gpa for academic success in industrial engineering classes," Int J. Humanities and Social Science, vol. 6, 2012, pp.139-142.

[15] J. M. Laguador, "Observed classroom behaviour as predictor of the major examination results in advanced statistics of BS Industrial Engineering Students. Int J. Management, IT and Engineering, 2013, vol. 3, no.7, p. 349.

[16] D. Moldabayev, J. A, Menicucci, S. Al-Zubaidy, and N. Abdulaziz, "March. Attendance, performance and culture Experience of the School of Engineering, Nazarbayev UniversityAn update," In Global Engineering Education Conference (EDUCON), 2013 IEEE, pp. 5-10.

[17] R. McCool, S. Kelly, M. Maguire, D. Clarke and D. Loughran, "Factors which influence the academic performance of level 7 engineering students," AISHE-J: The All Ireland J. of Teaching and Learning in Higher Education, 2015, vol. 7, no. 2.

[18] Building Regulations, Approved Document M: Access to and use of buildings, ISBN 978185946747 3, vol 1, section 1.18, p. 9, 2010.

[19] A. Lahtela, M. Hassinen and V. Jylha, "Rfid and nfe in healthcare: Safety of hospitals medication care," Pervasive Computing Technologies for Healthcare 2008, Pervasive-Health. Second International Conference, Feb 2008. pp. 241-244.

[20] G. Tewkesbury, D. Sanders, M. Haddad, N. Bausch, A. Gegov, and O.M. Okonor, "Task programming methodology for powered wheelchairs," Adv Intell Syst, Springer, IEEE SAI Intelligent Systems Conference 2019, London, United Kingdom, 5/09/19, Vol. 1 pp. 711-720, 2019.

[21] M. Haddad, D. Sanders, G. Tewkesbury, A. Gegov, M. Hassan Sayed, and F. Ikwan, "Initial results from using Preference Ranking Organization METHods for Enrichment of Evaluations to help steer a powered wheelchair,", Adv Intell Syst, vol. 1037, Springer, pp. 648-661, 2019.

[22] N. Bausch, P. Shilling, D. Sanders, M. Haddad, O. M. Okonor, and G. Tewkesbury, "Indoor location and collision feedback for a powered wheelchair system using machine learning," Adv Intell Syst, Springer, IEEE SAI Intelligent Systems Conference 2019, London, UK, 5/09/19, Vol. 1 pp. 721-739, 2019.

[23] D. Sanders, M. Langner, and G. Tewkesbury, "Improving wheelchair- driving using a sensor system to control wheelchairveer and variable-switches as an alternative to digital-switches or joysticks," Ind Rob: An int' jnl, vol. 37, no. 2, pp.151-167, 2010.

[24] M. Haddad, D. Sanders, and G. Tewkesbury, "Selecting a discrete Multiple Criteria Decision Making method to decide on a corporate relocation," Archives of Business Research, vol. 7, no. 5, pp. 48-67, 2019 